\title{
ANÁLISE DA VULNERABILIDADE NATURAL DA PAISAGEM EM RELAÇÃO AOS DIFERENTES NÍVEIS DE OCUPAÇÃO DA BACIA HIDROGRÁFICA DO RIO VERMELHO, ESTADO DE GOIÁS
}

\section{Analysis of the landscape natural vulnerability relatively to the differente levels of occupation in the Rio Vermelho watershed, Goiás State, Brazil}

\author{
Pedro Alves Vieira \\ Universidade Estadual de Goiás, Cidade de Goiás, Goiás, Brasil \\ gelpedrovieira@gmail.com \\ Nilson Clementino Ferreira \\ Universidade Federal de Goiás, Goiânia, Goiás, Brasil \\ nclferreira@gmail.com \\ Laerte Guimarães Ferreira \\ Universidade Federal de Goiás, Goiânia, Goiás, Brasil \\ laerte@ufg.br
}

Artigo recebido em 03/10/2013 e aceito para publicação em 22/05/2014.

RESUMO: A bacia hidrográfica do Rio Vermelho, situada no Estado de Goiás, possui uma elevada geodiversidade, com terrenos que vão do Arqueano ao Holocêno, e um proeminente registro tectônico impresso. Da mesma forma, ao longo de seu processo histórico de ocupação, tem sido impactada por variadas atividades de utilização do solo e do subsolo, o que acarretou tanto o empobrecimento da biodiversidade, quanto a modificação do seu aspecto físico, sendo expressiva a ocorrência de processos erosivos e acúmulos de sedimentos em razão da dinâmica de entrada e saída de energia e matéria do sistema natural. Neste trabalho, o qual teve por base a elaboração e análise do mapa de entropia do relevo para toda a área da bacia $\left(\sim 11.000 \mathrm{~km}^{2}\right)$, foi possível identificar áreas mais suscetíveis à atuação de processos morfogenéticos e, portanto, mais vulneráveis à ocupação, à exemplo das áreas próximas à foz da bacia, cujos valores de entropia são coerentes com a diversidade de usos e intervenções sobre o complexo sistema fluvial no entorno do canal principal do Rio Vermelho. Em que pese a necessidade de análises adicionais, à escalas de maior detalhe, nossos resultados demonstram o potencial da análise da entropia do relevo como ferramenta importante para identificar áreas com energia potencial disponível para realização de trabalho geomorfológico e, portanto, mais vulneráveis à ocupação (i.e. sujeitas a enchentes, inundações e deslizamentos de terras).

Palavras-chave: Entropia do Relevo, Bioma Cerrado, Vulnerabilidade da Paisagem, Bacia Hidrográfica.

\begin{abstract}
The Rio Vermelho watershed, located in the Goiás State, shows a great geodiversity, with terrains ranging from the Arquean to the Holocene, in addition to a proeminent tectonic record. Likewise, throughout its occupation history, it has been impacted by a variety of surface and underground activities, which resulted in biodiversity impovereshment, as well as physical modifications, particularly progressive erosion processes and sediment accumulation, as a function of the dynamic incoming and outcoming of matter and energy from the natural system. In this work, based on the elaboration and analysis of an entropy map for the entire basin area $\left(\sim 11,000 \mathrm{~km}^{2}\right)$, it was possible to identify areas more susceptible to morphogenetic processes
\end{abstract}


Análise da vulnerabilidade natural da paisagem em relação aos diferentes níveis de ocupação da bacia hidrográfica do Rio Vermelho, Estado de Goiás

Pedro Alves Vieira, Nilson Clementino Ferreira, Laerte Guimarães Ferreira

and, therefore, more vulnerable to land use and occupation. As an example of such areas, are those near the basin delta, where entropy values are compatible with the diversity of land uses and interventions over the complex fluvial system around the main Rio Vermelho channel. In spite the need of further analysis, at more detailed scales, our results clearly demonstrate the potential of the landscape entropy as an important tool for the identification of areas with more potential energy available for the geomorphological work and, therefore, more vulnerable to occupation (i.e. subject to floods and landslides).

Keywords: Landscape Entropy, Cerrado Biome, Landscape Vulnerability, Watershed.

\section{INTRODUÇÃO}

O Estado de Goiás, com $340.117 \mathrm{Km}^{2}$, encontra-se completamente inserido no bioma Cerrado, representando, portanto, cerca de $20 \%$ dos estimados dois milhões de $\mathrm{Km}^{2}$ deste importante domínio ecogeográfico. Os terrenos Arqueanos que sustentam o bioma Cerrado, localizados em território goiano, perfazem cerca de $20.000 \mathrm{~km}^{2}$ do chamado "Maciço de Goiás", recobrindo uma faixa entre $16^{\circ}$ e $14^{\circ}$ de latitude sul e $49^{\circ}$ a $51^{\circ}$ de longitude oeste, desde o município de Mossâmedes, ao sul, até Santa Terezinha de Goiás, ao norte, dos quais, aproximadamente, $80 \%$ são complexos granito-gnáissicos e $20 \%$ greenstone belts (Teixeira, 1981; Montalvão, 1985; Resende et al., 1998; Jost et al., 2005). Pode-se dizer que o "maciço de Goiás" possui uma alta geodiversidade, em função de uma história geológica muito antiga, a qual imprimiu características morfológica e pedológica e uma estruturação tectônica e hidrológica peculiares. Por isso, possui alto potencial mineral (Tomazzoli, 1985; Fortes, 1995; Resende et al., 1998), associado, principalmente, às rochas supracrustais, e figura, desde o início da história de ocupação do Cerrado, como principal atrativo da mineração, que teve seu início com a descoberta do minério de ouro, já no século XVIII (Estevam, 1998).

Este trabalho, que tem por referência o pressuposto de que os processos morfogenéticos estão intrinsicamente associados à dinâmica de evolução natural da superfície terrestre (Strahler,1952; Christofoletti, 1980; Casseti, 1991), bem como à interdependência de alimentação e retroalimentação entre as inúmeras variáveis envolvidas no processo da construção da paisagem natural (Crepani et al., 1996; Crepani et al., 2006), buscou avaliar as possíveis relações entre entropia do relevo (Phillips, 2006; Nunes et al., 2008) e vulnerabilidades naturais e antrópicas para a bacia hidrográfica do Rio Vermelho, localizada na porção oeste do Estado de Goiás e caracterizada por uma complexa história geológica e uma intensa ocupação e uso do solo, que vem acarretando expressivos impactos ambientais no sistema hidrológico local. Especificamente, foram avaliados os processos de ocupação e uso das terras e suas repercussões sobre as vulnerabilidades naturais da bacia, ao mesmo tempo em que buscou-se avaliar o significado e correlação da entropia do relevo no contexto das variáveis naturais identificadas e caracterizadas, e respectivas respostas ao maior ou menor trabalho geomorfológico. Nossos resultados fornecem subsídios orientadores para formulação de políticas públicas para a gestão territorial e ambiental dos municípios que integram a bacia hidrográfica do Rio Vermelho.

\section{ÁREA DE ESTUDO}

A bacia hidrográfica do Rio Vermelho, localiza-se na região oeste do Estado de Goiás, ocupando uma área de $10.824 \mathrm{~km}^{2}$, entre os municípios goianos de Cidade de Goiás (alta bacia) e Aruanã (baixa bacia), entre os paralelos $14^{\circ} 55^{\prime} \mathrm{e}$ $16^{\circ} 20^{\prime}$ Sul e os meridianos $50^{\circ} 00^{\prime}$ e $51^{\circ} 30^{\prime \prime}$ Oeste. Aproximadamente $5.000 \mathrm{~km}^{2}$ encontram-se sobre terrenos arqueanos granito-gnáissicos e greenstone belts. Por outro lado, toda a parte baixa e média da bacia, o que equivale a aproximadamente $50 \%$ da sua área, tem no seu arcabouço geológico uma cobertura detrítico-laterítica de idades Terciárias/ Quaternárias, composta por sedimentos arenosos da formação Araguaia (Quaternário) e depósitos arenosos inconsolidados de planície aluvial (Holoceno) (Valente, 2007). Aliada a esta complexa história geológica, ressalta-se a longínqua e impar história de uso e ocupação da terra nesta bacia, a qual remonta à exploração dos depósitos aluvionares de 
metais metálicos a partir do século XVIII (Silva, 1982; Estevam, 1998), cujos severos impactos ambientais ao sistema hidrológico são evidentes nos dias atuais. Intersectam seus limites, os municípios de Cidade de Goiás, Aruanã, Matrinchã, Britânia, Jussara, Santa Fé de Goiás, Fazenda Nova, Novo Brasil, Buriti de Goiás, Faina e Itapirapuã (totalmente inserido na bacia) (Figura 1).

Figura 1. Mapa de localização da bacia do Rio Vermelho no Estado de Goiás, com destaque para os municípios que intersectam ou integram os seus limites.

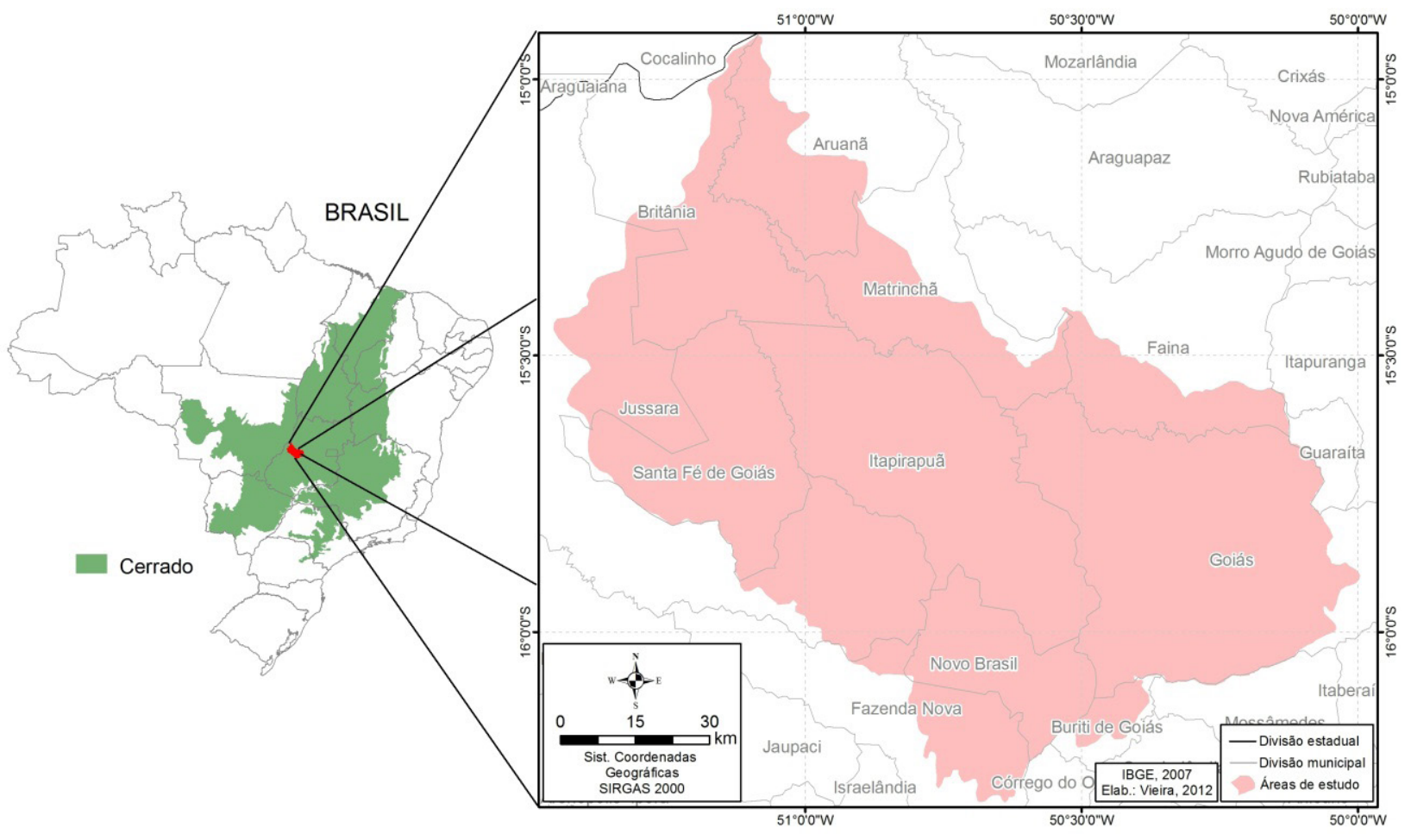

Elaboração dos autores.

\section{ASPECTOS GEOLÓGICOS}

$\mathrm{Na}$ área de estudo, os terrenos arqueanos, configurados pelo Maciço de Goiás, com seus granito-gnáisses e greenstone belts, sustentam toda a média e alta bacia, apresentando uma proporção areal aproximada de $80 \%$ para os granitos-gnáisses (Lessa \& Andrade,1971; Baêta Jr., 1978; Teixeira, 1981; Drago, 1981; Baêta Jr. et al, 1998; Souza et al., 1999) e 20\% para os greenstone belts (Tassinari \& Montalvão, 1980; Tomazzoli, 1985; Resende et al., 1998; Jost et $a l,, 2005)$, em cotas variando entre 450 e 850 metros.

De uma forma geral, os gnaisses, paleoproterozóicos, e granitos, neoproterozóicos, se concentram na porção oeste da bacia, nas regiões dos municípios de Novo Brasil, Fazenda Nova, Jussara e Itapirapuã, os gnáisses, granitos e quartzitos ao sul, no município de Cidade de Goiás, e os greenstone belts, a leste. Uma cobertura detrítico-laterítica, em forma de um terraço suspenso, acompanha os sistemas fluviais principais a partir da região do distrito de Uvá e o município de Itapirapuã, margeando os rios Uvá, Itapirapuã e Vermelho (Vieira, 2003; Jost et al., 2005; Valente, 2007; Bayer, 2010). Ao norte e noroeste da bacia, observamos uma ampla cobertura de sedimentos arenosos de composição quartzoza da Formação Araguaia, altamente lixiviados, com altitude variando de 230 a 200 metros (Vieira, 2003). Nesta região, o Rio Vermelho possui uma ampla planície de inundação associada à paleocanais e um complexo sistema lacustre, com ocorrência, na altitude de 200 metros, de depósitos síltico-arenosos holocênicos. 
Análise da vulnerabilidade natural da paisagem em relação aos diferentes níveis de ocupação da bacia hidrográfica do Rio Vermelho, Estado de Goiás

Pedro Alves Vieira, Nilson Clementino Ferreira, Laerte Guimarães Ferreira

\section{ASPECTOS GEOMORFOLÓGICOS}

A bacia hidrográfica do Rio Vermelho constitui-se em uma depressão fechada ao sul (logo acima do povoado de Areias), ponto de vergência de litologias dos greenstone belts e os quartzitos da Serra Dourada, na região denominada de Cabeça de Touro, e aberta a noroeste, com altitudes máximas de 600 metros e mínimas de 200 metros. A nordeste, limita-se com estruturas lineares (direções de $\mathrm{N} 55^{\circ} \mathrm{W}$ ), em altitudes entre 600 e 850 metros, sustentadas pelas Serras de Santa Rita, associadas aos greenstone belts (homônimo), cujos litótipos, dobrados e falhados, vão de metassedimentos a metavulcânicas. À sudeste, e a sul, limita-se com a Serra Dourada, com altitudes entre 800 e 1080 metros e relevo tipo Hogback, sustentada por uma sequência de quartzitos, xistos e metaconglomerados de idades proterozóicas, em cujo front se desenvolve um espesso colúvio, de uma matriz composta por areias e seixos de quartzos, o qual avança por sobre a bacia na forma de pequenos leques.

A rede hidrológica, sob forte influência tectônica, apresenta padrão dendrítico, tendo no Rio Vermelho seu principal sistema fluvial, cujas nascentes e foz, com altitudes de 900 metros e 220 metros, respectivamente, definem uma direção preferencial ESE-WNW. Na alta bacia, o fluxo do Rio Vermelho segue o contato estrutural definido por falhas entre os granitos-gnáisses do Complexo Uvá e os metassedimentos do greestone belt de Santa Rita, sendo os seus principais afluentes o rio Água Limpa, pela esquerda, e o rio Ferreira, pela margem direita.

A estruturação geomorfológica da bacia ocorre de sudoeste para nordeste, com grandes quantidades de canais intermitentes e nascentes instaladas nos cóluvios do sopé da Serra Dourada. Por se tratar de uma rede de drenagem que tem seus fluxos sobre um pavimento rochoso de rochas duras, devido influência tectônica, apresenta canais com uma série de rupturas de declive ao longo dos cursos, formando pequenas cachoeiras. A tectônica impressa no mosaico litológico que integra a bacia do Rio Vermelho apresenta um padrão de lineamento predominante de direção $\mathrm{N} 20^{\circ} \mathrm{W}, \mathrm{N} 20^{\circ} \mathrm{E}$ e N - S (Vieira, 2003; Valente, 2007; Bayer, 2010). Segundo Latrubesse \& Carvalho (2006), excluída a superfície de cimeira, representada pela Serra Dourada e pelos greenstone belts, com altitudes superiores a 800 metros, a bacia apresenta três superfícies de aplainamento: SA1, SA2 e SA3, da mais antiga para a mais recente, com altitudes de 600 metros, 500 metros e 400 metros, respectivamente. Especificamente em relação à superfície SA3, representada pelos vales encaixados, se encontra instalado o sistema hidrológico atual.

\section{ASPECTOS PEDOLÓGICOS}

De um modo geral, o sistema pedológico da bacia hidrográfica do Rio Vermelho apresenta um saprólito com espessuras entre 2 e 3 metros, de caráter caolínico, de cor esbranquiçada, altamente lixiviado e friável. Em relação aos terrenos arqueanos, em altitudes próximas de 400 metros, bem como aos cóluvios do front da Serra Dourada, em altitudes próximas a 650 metros, predomina uma matriz arenosa, com uma cobertura superficial de seixos quartzosos. Sobre as meta-ultramáficas, em altitudes aproximadas de 500 metros, desenvolve-se um saprólito ferruginoso de matriz argilosa. Em áreas localizadas na alta, média e, de forma mais restrita, baixa bacia, ocorre uma ampla cobertura laterítica, com espessura aproximada de 3 metros (Lacerda Filho \& Frasca, 2008), enquanto que na baixa bacia, um saprolito arenoso, com matriz de areia quartzoza média a fina, bem selecionada, de alta permeabilidade e porosidade, sustenta uma superfície plana, em cotas altimétricas de 230 metros, sobre os sedimentos da Formação Araguaia. Nestas áreas também podem ser observados níveis de laterita nodular, geralmente a partir de 2 metros de profundidade.

\section{ASPECTOS CLIMÁTICOS}

A configuração topográfica do Estado de Goiás influencia diretamente na distribuição das temperaturas e precipitações médias mensais, na medida em que se constata valores maiores de pluviosidade e valores menores de temperatura nas localidades de maiores altitudes, posicionadas na região leste do estado, e menores índices de pluviosidade e maiores temperatura nas áreas rebaixadas inseridas no planalto, ou então nas áreas posicionadas ao longo dos vales dos rios Araguaia/Vermelho, Paranã e Paranaíba (Campos, 2001; Pereira et al., 2008). 
Em geral, temperaturas médias mensais mais elevadas predominam no mês de dezembro, com valores entre 23 e $26^{\circ} \mathrm{C}$, durante o verão. A posição latitudinal de Goiás (entre 13 e $19^{\circ} \mathrm{Sul}$ ), sua proximidade com a região Amazônica e sua continentalidade, favorecem a atuação da massa Equatorial Continental que, ao penetrar no Estado de Goiás, através das Depressões Interplanálticas dos Rios Araguaia e Paranã, proporciona o aumento das temperaturas. Especificamente em relaçao à bacia hidrográfica do Rio Vermelho, inserida no setor noroeste do estado de Goiás e sob influência da Depressão Interplanáltica do Rio Araguaia, esta se caracteriza pela presença de altas temperaturas ao longo do ano, com médias mensais variando de 23 a $28^{\circ} \mathrm{C}$ (com temperaturas mínimas e máximas de 20 e $32{ }^{\circ} \mathrm{C}$, respectivamente).

Quanto ao comportamento espacial e temporal das pluviosidades no Estado de Goiás, este apresenta grande variação, com precipitações médias entre $1 \mathrm{~mm}$, durante o periodo seco (junho a agosto), e $450 \mathrm{~mm}$, durante o periodo mais chuvoso (dezembro a março). Especificamente em relação à bacia do Rio Vermelho, valores médios mensais (2000 a 2010) de 0 a 38 e de 397 a $161 \mathrm{~mm}$ foram observados nos meses de junho a agosto e dezembro a março, respectivamente (Figura 2).

Figura 2. Precipitação média mensal (2000 a 2010) para toda a região delimitada pela bacia do Rio Vermelho (dados TRMM / Tropical Rainfall Measurement Mission).

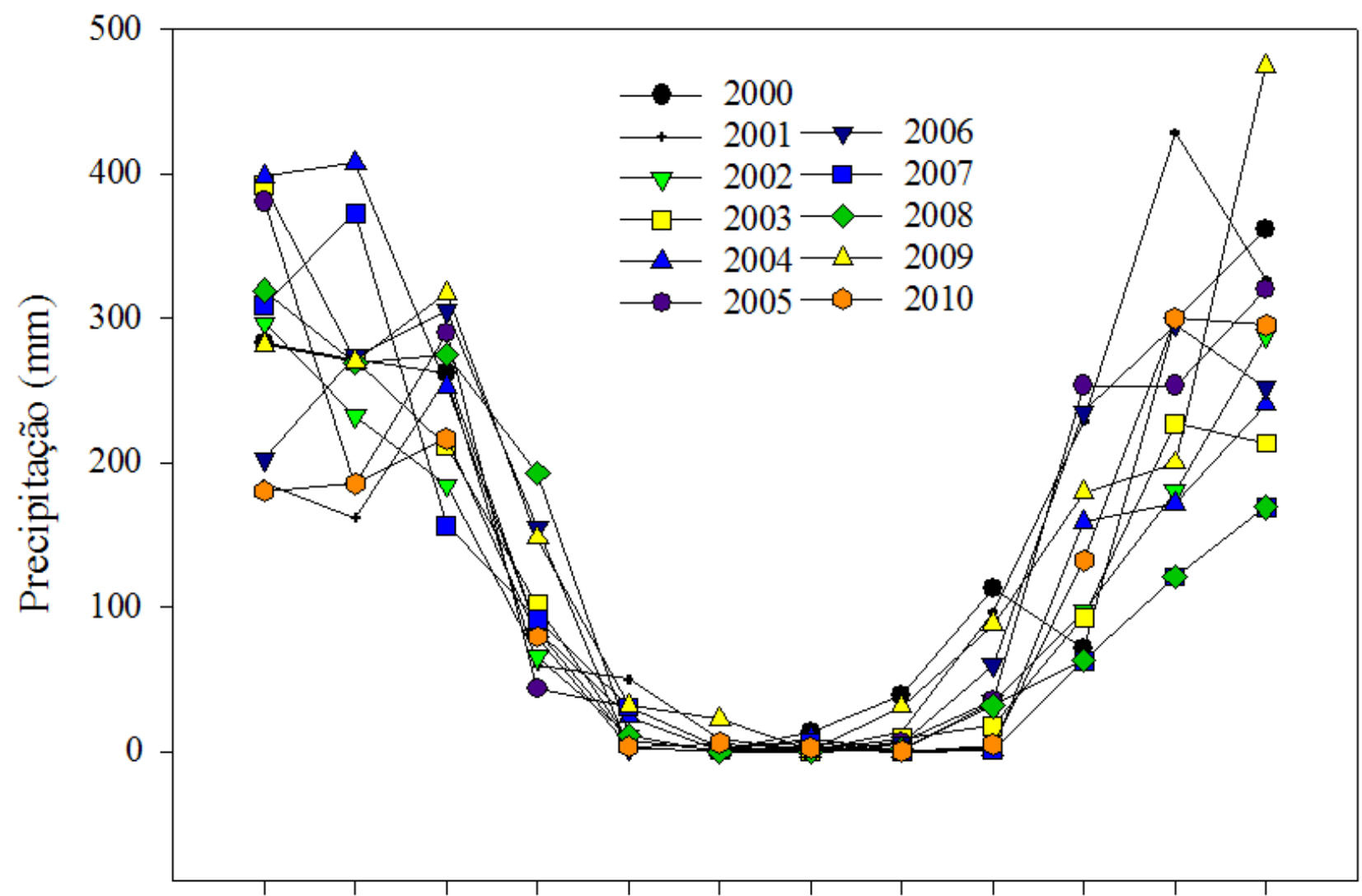

Jan. Fev. Mar. Abr. Maio Jun. Jul. Ago. Set. Out. Nov. Dez.

\section{Meses}

Elaboração dos autores. 
Análise da vulnerabilidade natural da paisagem em relação aos diferentes níveis de ocupação da bacia hidrográfica do Rio Vermelho, Estado de Goiás

Pedro Alves Vieira, Nilson Clementino Ferreira, Laerte Guimarães Ferreira

\section{ASPECTOS HIDROLÓGICOS}

Com base nos dados de cota e vazão disponíveis para a estação Balneário Cachoeira Grande, aproximadamente $3 \mathrm{~km}$ a jusante do sitio urbano da Cidade de Goiás, o regime hidrológico do sistema da bacia do Rio Vermelho se caracteriza por picos definidos de enchentes e vazantes acompanhando, em parte, as precipitações da região (Figura 3). É importante ressaltar que os elevados valores altimétricos da bacia, associados às rochas do embasamento cristalino, favorecem a presença de fluxos concentrados, em curto espaço de tempo, em resposta às precipitações.

Figura 3. Relação entre cota (Rio Vermelho, Balneário Cachoeira Grande, Cidade de Goiás) e precipitação, para o período entre 1996 e 2001 (média mensal).

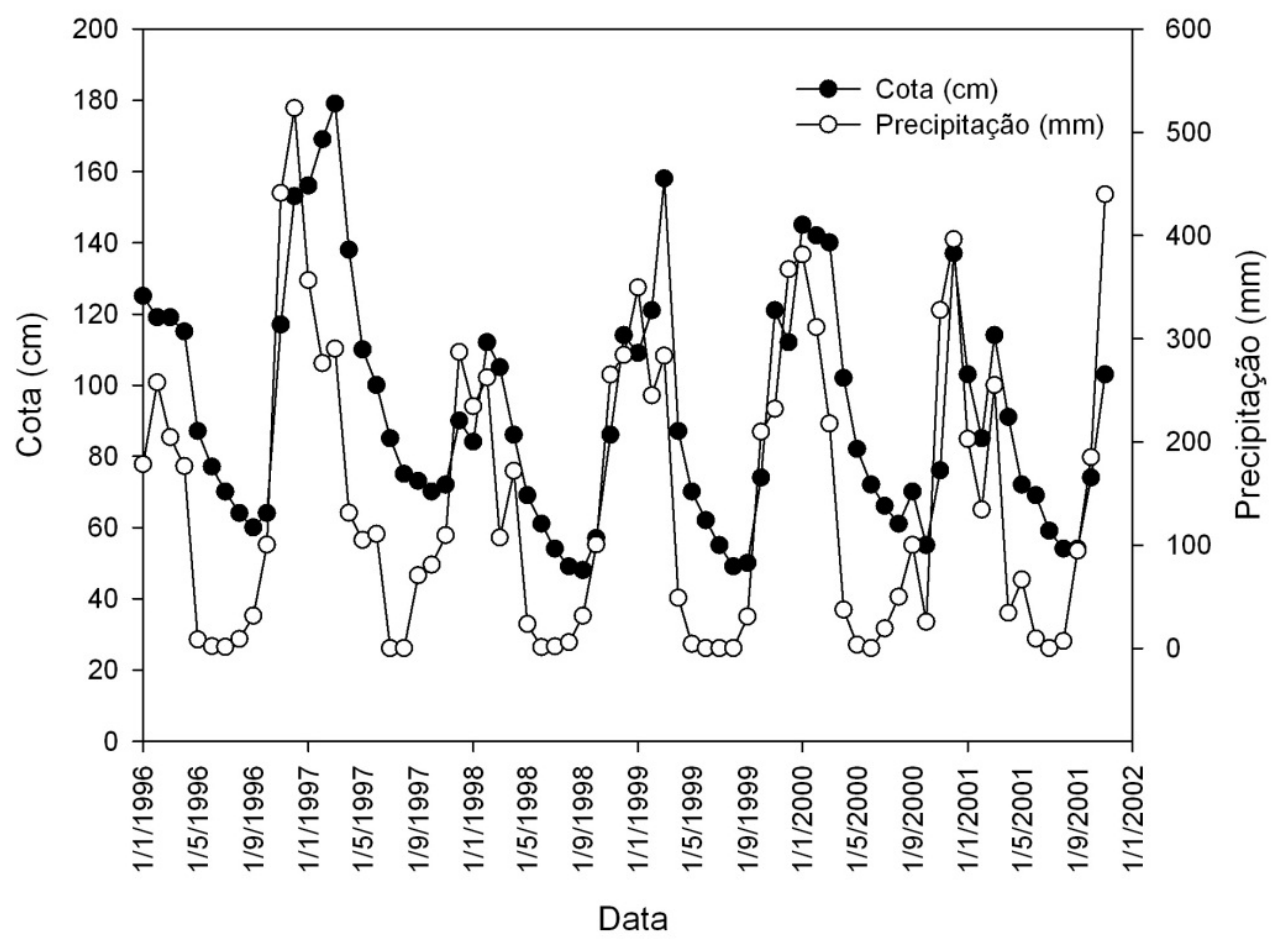

Elaboração dos autores.

\section{ASPECTOS DE USO E OCUPAÇÃO}

Em geral, a dinâmica de ocupação do território goiano seguiu o padrão nacional, ou seja, do leste para o oeste, e do sul para o norte, com a instalação de núcleos de povoamento resultantes de processos históricos marcantes, como as bandeiras no século XVII e a descoberta de ouro, no século XVIII (Silva, 1982; Estevam, 1998). No século XIX, com o declínio da mineração, o território goiano passou ser ocupado pela pecuária - que vinha acompanhando a mineração, e uma agricultura de subsistência - "o roçado". As regiões sul e sudoeste do estado foram as preferencialmente ocupadas pelos núcleos familiares que passaram a utilizar os "espaços vazios" deixados pela mineração desde o século XVII (Martins, 1997), haja vista apresentarem topografia plana, resultado de uma cobertura sedimentar, solos com boa fertilidade natural, associados aos depósitos de basaltos da bacia do Paraná, e grandes áreas de cerrado aberto (pastagem natural). A partir das décadas de 40 e 50, do século XX, a região Centro-Oeste e o Estado de Goiás, em particular, passaram por profundas transformações, em função das políticas de interiorização do desenvolvimento e integração nacional (Anacleto \& Miziara, 2006). A ocupação da bacia do Rio Vermelho, com importantes áreas para mineração, com lavra de ouro sobre os greenstone belts, das metaultramáficas 
Análise da vulnerabilidade natural da paisagem em relação aos diferentes níveis de ocupação da bacia hidrográfica do Rio Vermelho,

Estado de Goiás

Pedro Alves Vieira, Nilson Clementino Ferreira, Laerte Guimarães Ferreira

e granitos para revestimento, seixos rolados e areia para construção civil e argila para cerâmica vermelha, seguiu o mesmo modelo de ocupação do Estado de Goiás, influenciado pela mineração. Em fato, mais de $50 \%$ de seu subsolo encontra-se em fase de Alvará de Pesquisa Mineral para os mais variados bens minerais (DNPM, 2010). Já do ponto de vista de uso para agropecuária, de acordo com Instituto Nacional de Colonização e Reforma Agrária (INCRA), em 2011, o Estado de Goiás possuía 288 projetos de assentamento
Rurais, sendo que destes, 22 se encontravam na alta bacia do Rio Vermelho. Tanto nestes assentamentos, quanto na bacia como um todo, cuja área ocupada totaliza aproximadamente $65 \%$ (Figura 4), predominam a pecuária, com três padrões distintos de pastagens: um mosaico que associa pastagem e remanescentes para alta bacia, uma pastagem com padrão geométrico bem definido, evidenciando um uso com maior padrão tecnológico na baixa bacia e uma zona de transição, na média bacia mesclando os dois padrões.

Figura 4. Cobertura e uso do solo na bacia do Rio Vermelho (2008).

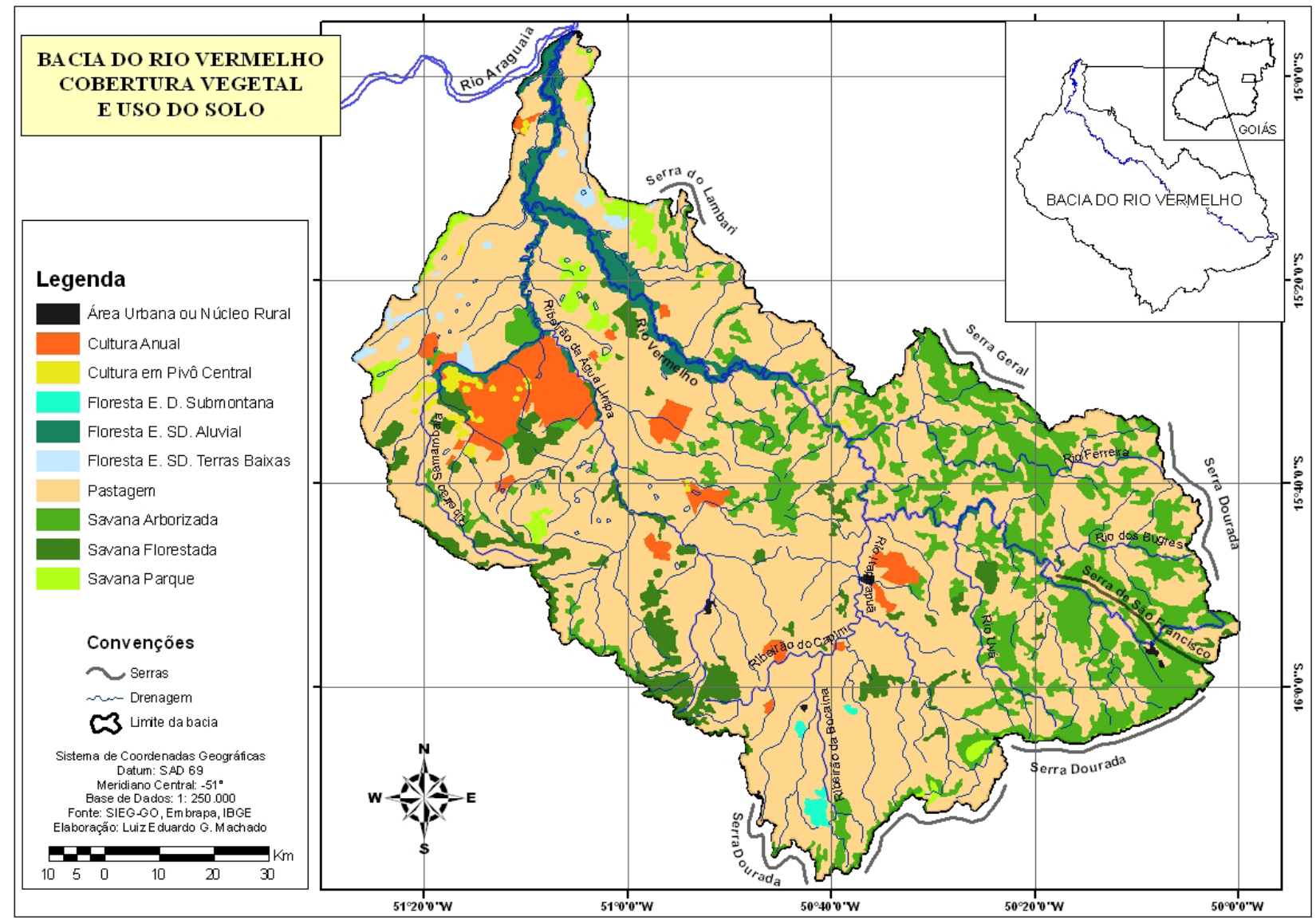

Elaboração dos autores.

\section{METODOLOGIA}

Inicialmente, e considerando a totalidade da área abrangida pela bacia hidrográfica do Rio Vermelho, foi organizada uma base de dados geográficos vetoriais (ex. limites políticos e administrativos, drenagens, sistema viário, etc) (disponíveis através do Sistema de Informações Estasticas e Geograficas para o Estado de Goias - SIEG: www.sieg.go.gov.br/) e satelitários (imagens Landsat 5-TM, cenas 239/70 e 239/71, obtidas em agosto de 2008), a partir dos quais elaborou-se o mapa de cobertura e uso do solo (Figura 4), validado por meio de três inspeções em campo, realizadas em junho, novembro e dezembro de 2010.

Para fins de análise, e tendo por base a relação direta entre hipsometria, geomorfologia e 
Análise da vulnerabilidade natural da paisagem em relação aos diferentes níveis de ocupação da bacia hidrográfica do Rio Vermelho, Estado de Goiás

Pedro Alves Vieira, Nilson Clementino Ferreira, Laerte Guimarães Ferreira

arcabouço geológico, a bacia do Rio Vermelho foi dividida em quatro domínios principais: Superfície de cimeira (com variação altimétrica entre 1.050 e 800 metros), sustentada pelos greenstone belts de Santa Rita e quartzitos da Serra Dourada; Superficie de aplainamento SA1 (entre 800 e 600 metros), com relevo ondulado a fortemente ondulado, sob forte controle tectônico, definida pelos gnáisses, cóluvios do Hogback Serra Dourada, metaultramáficas e partes arrasadas dos greenstone belts; $\underline{\text { Superfície }}$ de aplainamento SA2 (com variação altimétrica de 600 a 450 metros), definida por granitos, gnáisses, cobertura detríto-laterítica; e Superfície de aplainamento SA3 (em altitudes de 450 a 220 metros), associada às coberturas detrítico-lateríticas e sedimentos arenosos da Formação Araguaia, bem como sedimentos inconsolidados de idades holocênicas da planície aluvial (Figura 5).

Figura 5. Variação hipsométrica na bacia do vermelho (dados SRTM), comparativamente às superfícies de aplainamento (detalhe) e lineamentos estruturais.

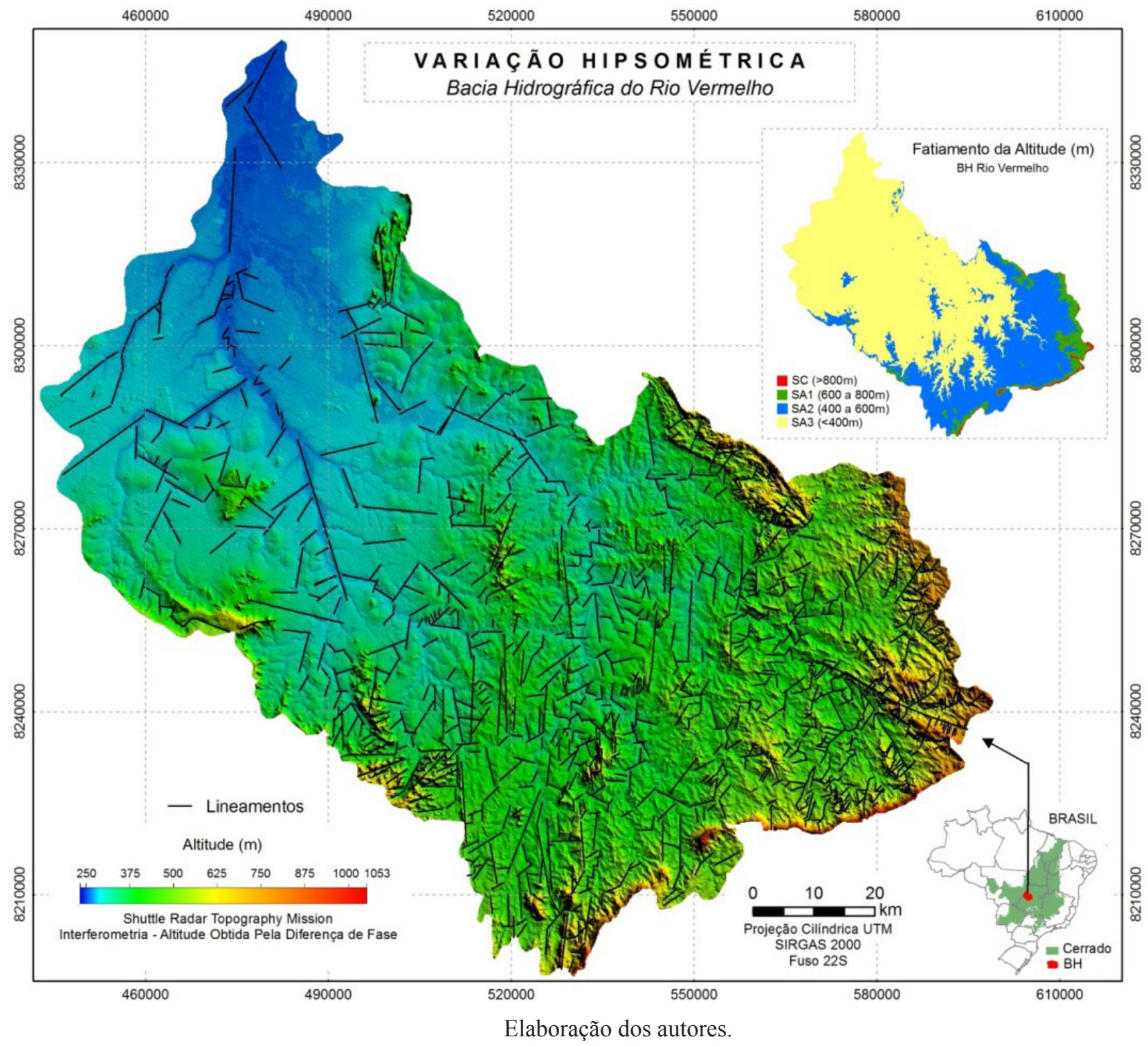

Soc. \& Nat., Uberlândia, 26 (2): 385-400, mai/ago/2014 
Em relação à declividade, esta foi dividida nas seguintes classes, de $0-8,0 \% ; 8,1-20 \% ; 20,1$ - $45 \%$ e $>45 \%$, onde hipsometria, declividade e superfície de aplainamento se relacionam da seguinte forma: predomínio da declividade de 0 a $8,0 \%$ na faixa hipsométrica baixa e processos erosivos relacionados a Superfície de Aplainamento mais recente - SA3; $8,1-20 \%$, relacionada principalmente à hipsometria média e Superfície de Aplainamento SA2; $20,1-45 \%$ associada à hipsometria alta $\mathrm{e}$ Superfície de Aplainamento SA1; > 45\%, em áreas com altos valores hipsometricos, relacionados às superfícies de cimeira.

Especificamente para a elaboração do mapa de entropia do relevo, foram utilizadas as imagens topográficas disponibilizadas por meio do projeto Global Digital Elevation Model (Aster/GDEM), que realizou o processamento de 1,3 milhões de imagens adquiridas pelo sensor orbital ASTER, cobrindo a superfície terrestre entre as latitudes de $83^{\circ}$ norte e $83^{\circ}$ sul. Ao todo, o mosaico Aster/GDEM é composto por 22.895 imagens de $1^{\circ}$ por $1^{\circ}$, com resolução espacial de 30 metros e acuidade planimétrica e altimétrica de 30 e 20 metros, respectivamente (Rodrigues et al., 2010). Com base nestes dados altimétricos, e considerando-se operações de vizinhança em uma matriz de convolução quadrada de dimensão ( $\mathrm{n}$ x n), classificou-se a célula central, conforme a probabilidade da mesma ocorrer em outros locais da área compreendida pelo MDE, conforme a equação (1):

$$
P_{i}=\frac{n_{i}}{N}
$$

sendo que $P_{i}$ é a probabilidade de uma determinada célula de altitude $n_{i}$ ocorrer em uma matriz quadrada de convolução $\mathrm{N}$, de $\mathrm{n} \times \mathrm{n}$ células.

Em seguida aplicou-se a fórmula de cálculo de entropia, apresentada na equação (2):

$$
H=-\sum_{i=1}^{n} P_{i} \ln P_{i}
$$

sendo que $H$ é a entropia calculada, através do somatório dos produtos dos logaritmos naturais (ln) por suas respectivas probabilidades $P$.

As operações matemáticas necessárias para o mapeamento da entropia foram implementadas no sistema de informações geográficas ArcGIS 9.3, utilizado no processamento automático dos dados altimétricos.

De posse do mapa de entropia do relevo, foram realizados cruzamentos topológicos, com o intuito tanto de validar o método propriamente dito, quanto avaliar as áreas de vulnerabilidade potencial indicadas pelo mapa de entropia.

\section{RESULTADOS E DISCUSSÕES}

O mapa de entropia do relevo é mostrado na figura 6, em relação ao qual é importante ressaltar que, quando analisado como um produto separado das demais variáveis que compõe o sistema natural (geologia, relevo, solo, clima, tectônica, uso), serve apenas como indicativo da energia potencial disponível para produzir trabalho geomorfológico. Especificamente, valores de entropia elevados correspondem àquelas áreas em que houve um grande aporte (e distribuição) de energia, gerando significativos processos erosivos. Como consequência, temos terrenos aplainados, áreas estabilizadas e, em geral, áreas de baixa vulnerabilidade natural, com o predomínio de processos pedogenéticos sobre os morfogenéticos, à exemplo do que ocorre na baixa bacia, zona do exutório, umbral de parada dos processos geomorfológicos. Por outro lado, áreas com valores baixos de entropia caracterizam os terrenos com grande diversidade altimétrica e, portanto, com grande quantidade de energia potencial disponível no sistema, capaz de desencadear processos erosivos e induzir alta vulnerabilidade natural. 
Análise da vulnerabilidade natural da paisagem em relação aos diferentes níveis de ocupação da bacia hidrográfica do Rio Vermelho, Estado de Goiás

Pedro Alves Vieira, Nilson Clementino Ferreira, Laerte Guimarães Ferreira

Figura 6. Mapa de entropia do relevo para a bacia do Rio Vermelho, Goiás (círculos amarelos na figura indicam pontos amostrados em campo).

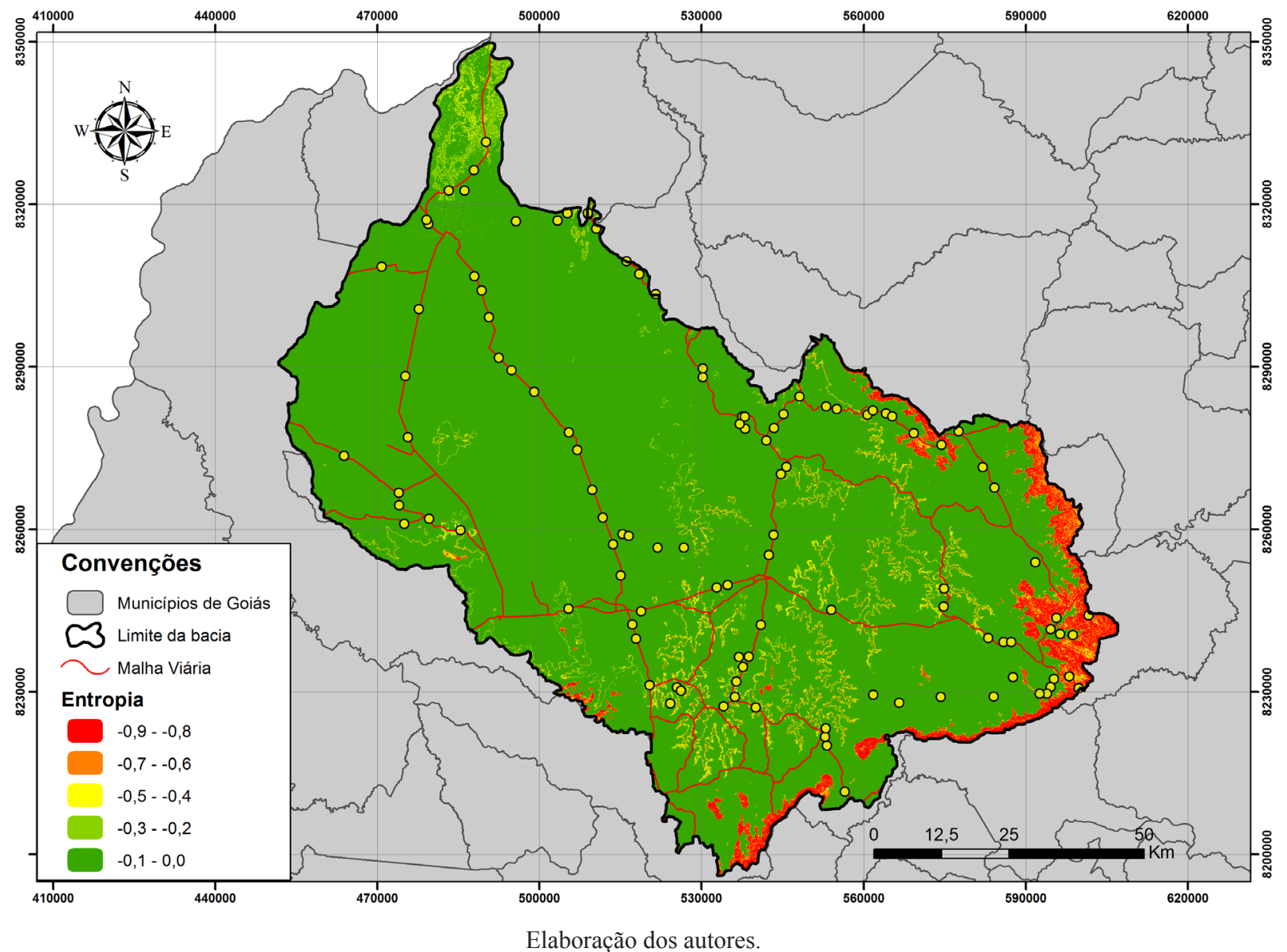

Em relação à distribuição dos valores de entropia (Figura 6), são possíveis as seguintes constatações gerais: 1) a classe de entropia baixa $(<-0,70)$ prevalece na alta bacia, associada à superfície de cimeira, ao sul, leste e oeste, em altitudes entre 1050 e 800 metros, associadas às estruturas que se encontram sob forte controle tectônico, como é o caso do Hogback Serra Dourada e a Serra de Santa Rita; 2$)$ entropias médias (-0,50 a -0,70), associadas aos sopés destas superfícies - fronte do Hogback da Serra Dourada, junto às estruturas lineares dos greenstone belts e porções da alta bacia, associadas à Superfície de Aplainamento SA1 (regiões sul, leste e oeste), em cotas altimétricas entre 800 e 600 metros; 3 ) entropias média a alta $(-0,20$ a $-0,50)$, encontradas junto às estruturas lineares com direcionamento norte - sul (figura 5), associadas à Superfície de Aplainamento SA2, em altitudes entre 600 e 450 metros, e ao norte, na foz do sistema associado à Superfície de Aplainamento
SA3, em altitudes entre 450 a 230 metros; 4) entropia alta $(-0,20$ a 0$)$, associada à Superfície de Aplainamento SA3 e ocupando toda baixa bacia, bem como permeando, através dos vales, em cotas altimétricas variando de 230 a 450 metros, a alta e média bacia.

Especificamente, na região sul - sudeste da bacia do Rio Vermelho observa-se uma forte correlação entre o mapa de entropia e a vulnerabilidade da paisagem, onde a classe de entropia baixa, associada aos terrenos arqueanos do Complexo Uvá e aos quartzitos da Serra Dourada, bem como à intensa movimentação tectônica, atuam no controle dos processos erosivos. Em fato, o predomínio de um sistema hidrológico dendrítico e escoamento superficial concentrado, resultados de uma superfície de aplainamento antiga (SA1), com altitudes acima de 550 metros, sugerem significativa atividade geomorfológica e alta vulnerabilidade natural, conforme ilustra a figura 7. 
Figura 7. Região sudeste da bacia (alta hipsometria), com destaque para o perfil do saprólito em várias posições na superfície de aplainamento SA1.

PL-3- Alta bacia(Fronte serra Dourada) $16^{\circ} 00^{\prime} 41,900 "$ / 50/07'18,200" $Z=564 \mathrm{~m}$

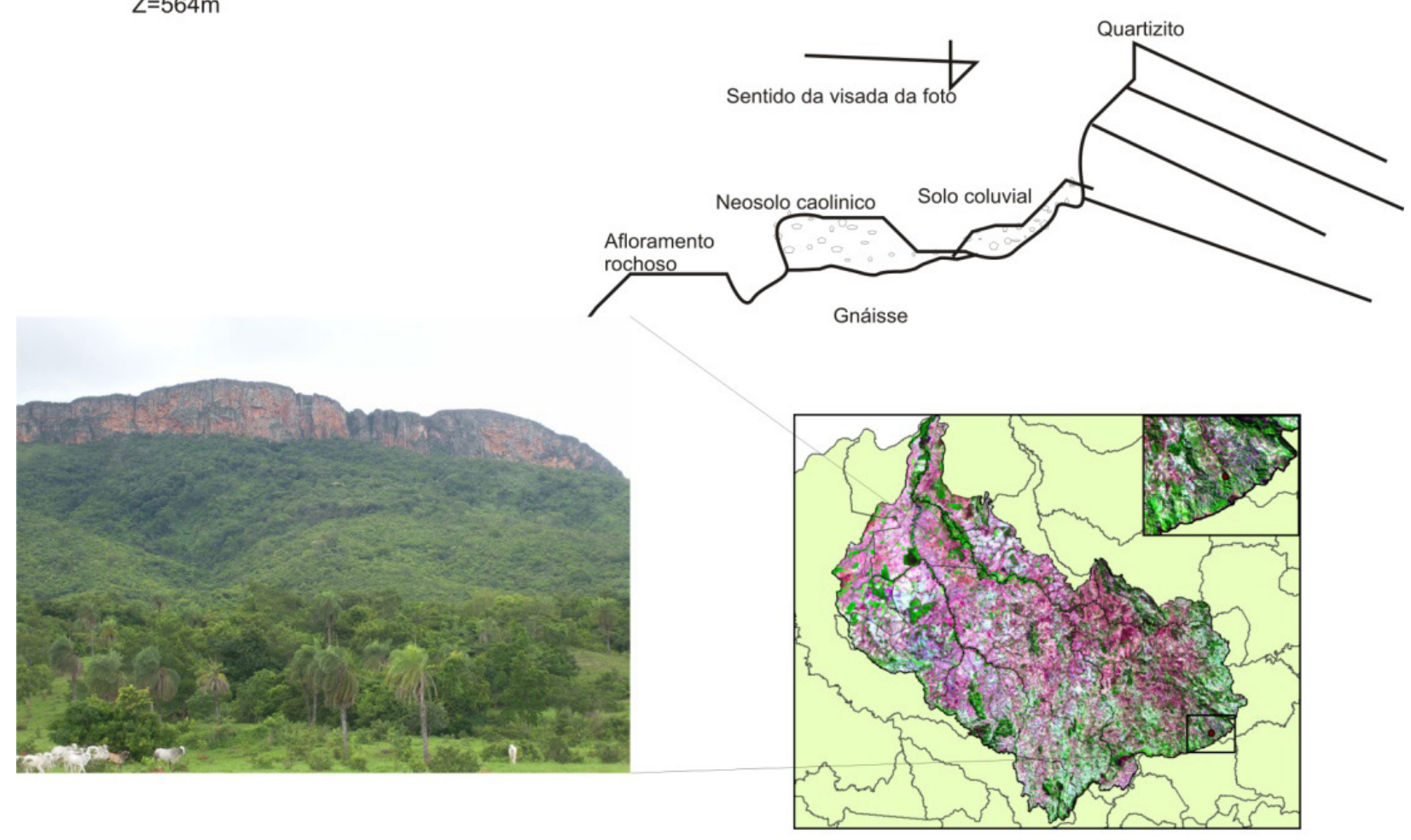

Elaboração dos autores.

Contudo, é interessante observar que nestas áreas, situadas em classes de entropia baixa e média - baixa, há também a inércia do sistema natural, com persistência das formas de relevo ao longo do tempo, o que resulta em baixa vulnerabilidade. Este é o caso de áreas sustentadas por rochas cristalinas, com ocupação e uso predominantemente de baixo impacto (parques, pastagens naturais, pastagens cultivadas, e pequena agricultura, com uso de "roçado" e tração animal), à exemplo das áreas situadas ao sul da bacia.

Boa correlação entre entropia e vulnerabili- dade também é encontrada na região oeste da bacia, situada sobre a Superfície de Aplainamento SA2 e sustentada por litótipos de idades Terciária/Quaternária (Cobertura Detrítico-Laterítica). Nesta região, predominam as classes de alta entropia e baixa vulnerabilidade a trabalhos geomorfológicos (Figura 8), haja vista cotas altimétricas moderadas ( 230 metros), saprólito acima dos dois metros de espessura, relevo plano, vertentes com rampas retas e longas, fundo de vales chatos, escoamento superficial difuso e predomínio de processos de iluviação. 
Análise da vulnerabilidade natural da paisagem em relação aos diferentes níveis de ocupação da bacia hidrográfica do Rio Vermelho, Estado de Goiás

Pedro Alves Vieira, Nilson Clementino Ferreira, Laerte Guimarães Ferreira

Figura 8. Superfície de Aplainamento SA2, região noroeste da bacia, com o predomínio de hipsometrias médias.
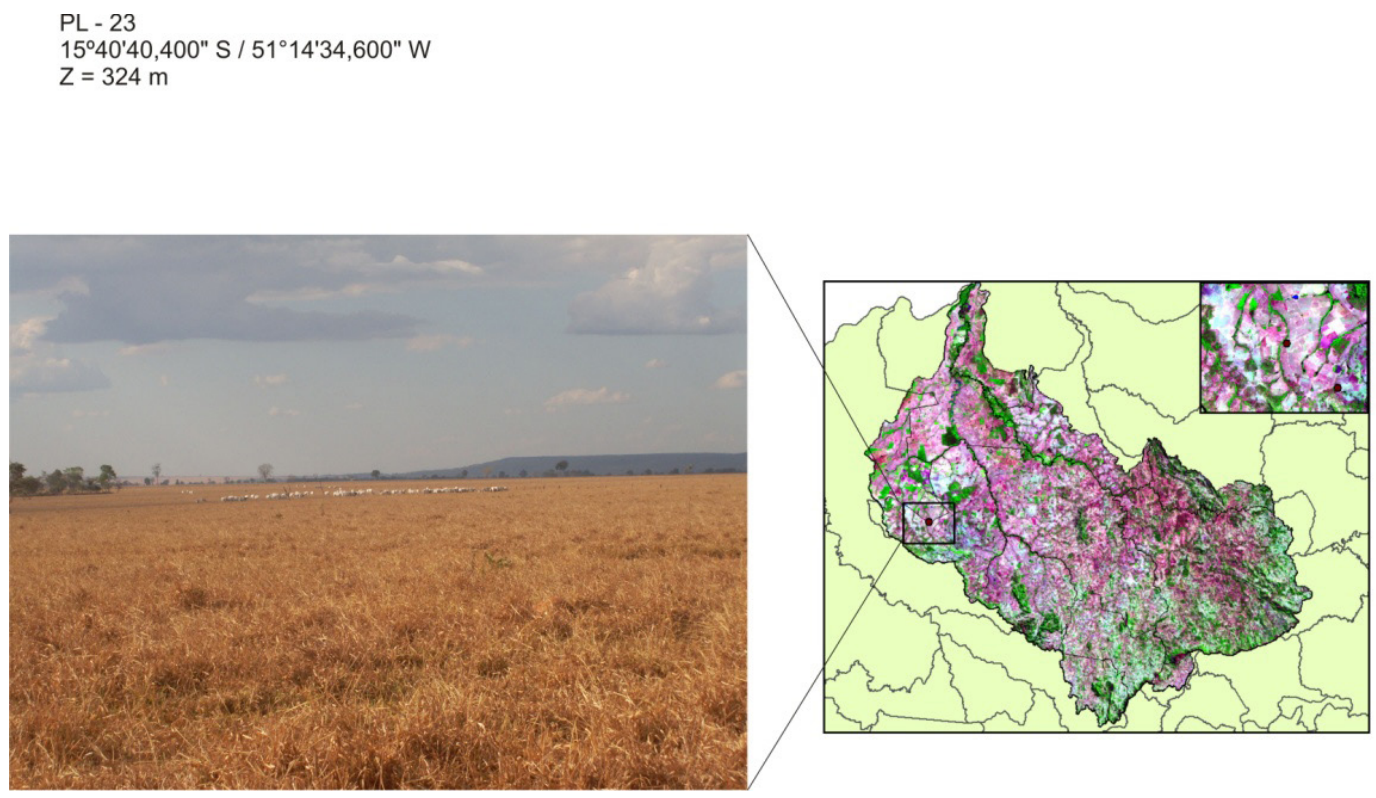

Elaboração dos autores.

Por outro lado, a região leste, também sobre a superfície SA2 (hipsometria média), apresenta baixa correlação entre entropia e vulnerabilidade. Nesta região, dominada por gnáisses e granitos (terrenos Arqueanos), dos quais resulta um espesso saprólito caolínico de matriz arenosa e friável ( $>2$ metros de profundidade), com um nível superficial pedregoso (seixos de quartzo), o escoamento superficial concentrado gera áreas de vulnerabilidade a processos erosivos (ravinas e boçorocas), apesar do predomínio das classes de entropia média a alta e processos de ocupação de baixo impacto (pastagem natural) (Figura 9).

Figura 9 - Superfície de Aplainamento SA2 (hipsometria média), predomínio de pastagens nativas, classes de entropia media a alta e vulnerabilidade a processos erosivos.
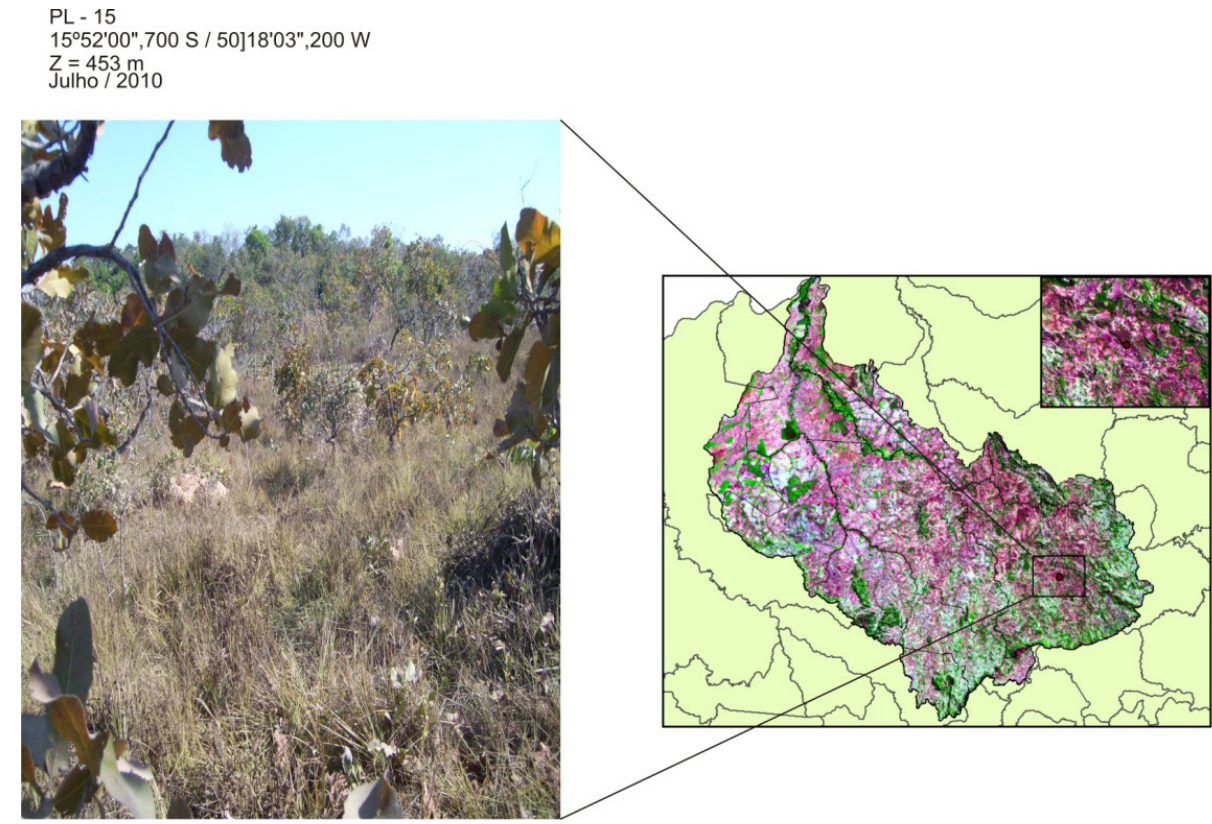

Elaboração dos autores.

Soc. \& Nat., Uberlândia, 26 (2): 385-400, mai/ago/2014 
Análise da vulnerabilidade natural da paisagem em relação aos diferentes níveis de ocupação da bacia hidrográfica do Rio Vermelho,

Estado de Goiás

Pedro Alves Vieira, Nilson Clementino Ferreira, Laerte Guimarães Ferreira

Na região norte (Superfície de Aplainamento SA3), caracterizada pelos sedimentos arenosos da Formação Araguaia, dos quais resulta espesso saprólito ( $>5$ metros de profundidade) com matriz arenosa (quartzosa) de boa porosidade e permeabilidade, e por um intenso processo de iluviação, em função de cotas hipsométricas baixas (abaixo de 300 metros), relevo plano, vales encaixados e um sistema hidrológico associado à paleocanais e lagos, há o predomínio das classes de alta entropia, em geral associadas a baixas vulnerabilidades, principalmente nas áreas distantes do sistema fluvial. Contudo, as áreas próximas à foz do Rio Vermelho podem apresentar alta resposta morfogenética e vulnerabilidade, haja vista a diversidade de usos (principalmente pastagens cultivadas e irrigadas e uso para recreação, em épocas de temporadas) e intervenções sobre os mosaicos de paleocanais, canais ativos e sistemas lacustres não associados aos canais fluviais.

Conforme a figura 10 , os sete municípios que apresentam as maiores proporções de área na classe de entropia baixa estão associadas aos terrenos arqueanos (Greenstone belts, granitos-gnáisses e quartzitos) e um forte controle téctônico: Goiás (26.505 ha), Faina (6.732 ha), Fazenda Nova (4.555 ha), Novo Brasil (2.185 ha), Jussara (1.255 ha), Buriti de Goiás (1.341 ha), Itapirapuã (595 ha), Santa Fé (241 ha) e Matrinchã (61 ha).

Figura 10. Classes de entropia (\%) por município e conforme superfícies de aplainamento.
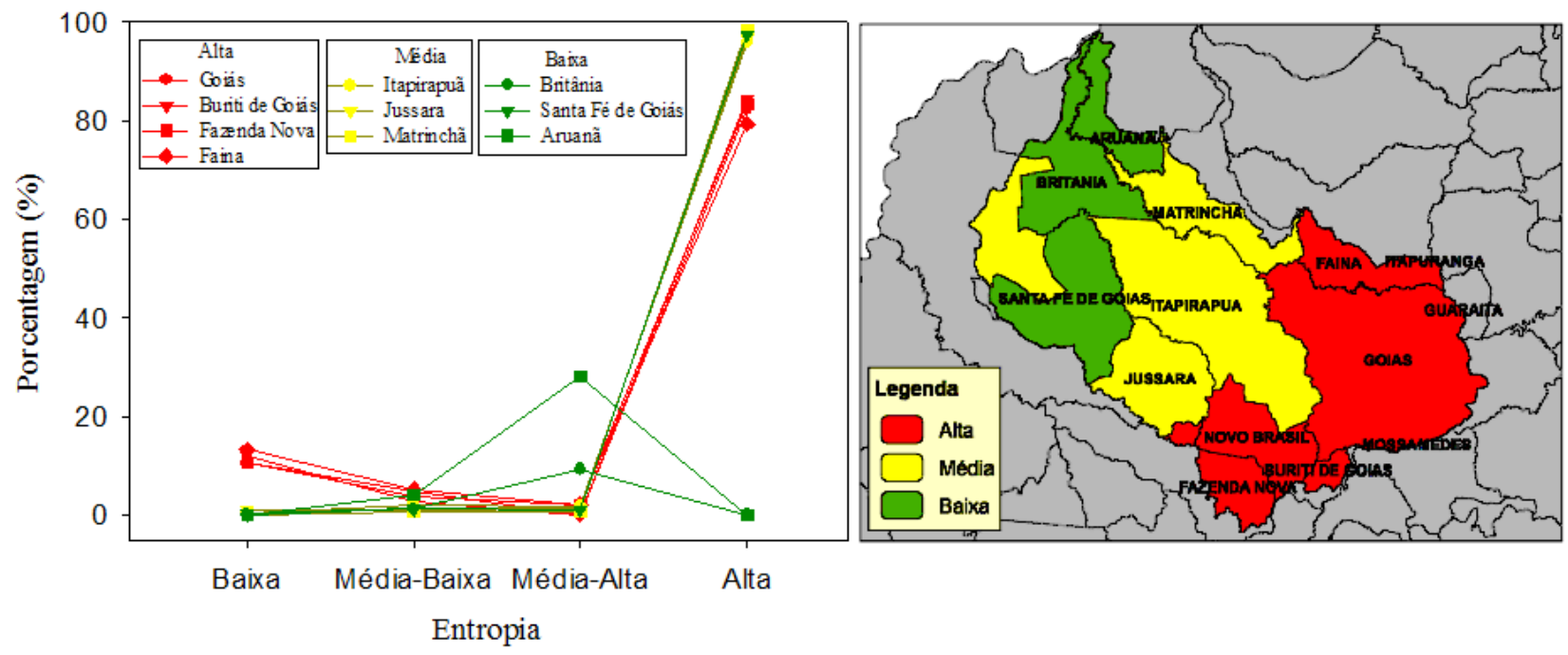

Elaboração dos autores.

A Cidade de Goiás, em particular, Patrimônio Mundial da Humanidade, encontra-se encravada no entorno de mais de vinte e seis mil hectares de áreas com alta vulnerabilidade, conforme a classe de entropia baixa, agravados por ocupações feitas de forma inadequada, principalmente ao longo da planície de inundação do rio Vermelho. Em fato, e tendo por base a análise integrada do mapa de cobertura e uso da terra, topografia e a rede de drenagem, bem como a legislação ambiental vigente, estima-se um passivo ambiental de aproximadamente sete mil hectares neste município, cujos impactos mais evidentes são perda de solo, acumulação de sedimentos nos leitos dos rios, solos rasos com pequena capacidade de retenção de água, além das recorrentes cheias e enchentes, potencializadas por precipitações intensas e concentradas. Exemplo mais marcante neste sentido, foi a tragédia ocorrida no dia 31 de dezembro de 2001 (AGIM, 2002), quando $140,9 \mathrm{~mm}$ de chuva, aproximadamente $45 \%$ do total para dezembro de 2001 (conforme dados TRMM), foram concentrados em pouco mais de 08 horas de precipitação, das 21:00 hs do dia 30, às $05: 00$ horas do dia 31 , com um retardo de chegada desta água ao canal principal de aproximadamente 04 horas, causando enchente de grandes proporções, que destruiu ou danificou parte significativa do acervo 
Análise da vulnerabilidade natural da paisagem em relação aos diferentes níveis de ocupação da bacia hidrográfica do Rio Vermelho, Estado de Goiás

Pedro Alves Vieira, Nilson Clementino Ferreira, Laerte Guimarães Ferreira

histórico. Tivesse este evento de precipitação iniciado na tarde do dia 30, e considerando o mesmo período de retardo do escoamento pluvial, o evento catastrófico teria ocorrido de madrugada, quando vidas, principalmente, teriam sido perdidas.

\section{CONSIDERAÇÕES FINAIS}

Este estudo buscou dimensionar a fragilidade do sistema natural da bacia Rio Vermelho, Estado de Goiás. Neste sentido, procedeu-se à análise integrada dos dados acerca da caracterização física do sistema, da dinâmica de uso e ocupação do solo e da entropia da relevo.

Em geral, foi possível constatar uma boa correlação entre as classes de entropia com o amplo conjunto de variáveis naturais (rochas, solos, tectônica, dados morfométricos de compartimento do relevo e o sistema hidrológico) e antrópicas (uso e ocupação do solo) consideradas, bem como com os diferentes níveis de vulnerabilidade do mosaico de paisagens que estas variáveis determinam e estruturam.

Embora a alta bacia, onde predomina as classes de baixa entropia (i.e. maior energia potencial disponível), seja mais suscetível a atuação de processos morfogenéticos e, portanto, mais vulnerável à ocupação, áreas da baixa bacia, principalmente aquelas próximas à foz do Rio Vermelho, merecem atenção e proteção, haja vista a ocorrência de cheias e processos de assoreamentos de canais, paleocanais e lagos. Em fato, e considerando que os processos de alimentação e retroalimentação conectam a bacia como um todo, sedimentos e contaminantes gerados na alta bacia, irão contaminar, aterrar e provocar o reajuste do nível de base nas áreas da baixa bacia, afetando, entre outros, a biodiversidade aquática.

Ainda em relação a região da foz da bacia, com áreas altamente niveladas pelos processos erosivos, é importante ressaltar o fato de ter sido possível identificar, apesar da escala trabalhada $(1: 100.000) \mathrm{e}$ do reduzido compartimento a que se restringe a faixa fluvial, áreas com entropia média, coerentes com o complexo sistema fluvial desenvolvido nas proximidades do canal principal do Rio Vermelho.

Assim, e ainda que os nossos resultados também indiquem a necessidade de um maior refinamento (aumento de escala) e realização de análises espaciais adicionais entre entropia, variáveis naturais e dinâmica de uso do solo, fica evidente o potencial do mapa de entropia do relevo como ferramenta importante para identificar áreas mais vulneráveis à ocupação (i.e. sujeitas a enchentes, inundações e deslizamentos de terras), bem como avaliar, em diferentes escalas, áreas com energia potencial disponível para realização de trabalho geomorfológico.

\section{AGRADECIMENTOS}

Este trabalho, desenvolvido no âmbito do Programa Multidisciplinar de Doutorado em Ciências Ambientais da Universidade Federal de Goiás (CIAMB / UFG), se insere entre as várias iniciativas do Laboratório de Processamento de Imagens e Geoprocessamento (LAPIG / UFG) voltadas ao monitoramento sistemático e gestão territorial do bioma Cerrado. O primeiro autor foi bolsista de doutorado da Coordenação de Aperfeiçoamento de Pessoal de Nível Superior (CAPES / MEC), enquanto o segundo e terceiro autores são bolsistas de Produtividade em Pesquisa (2 e 1C, respectivamente) do Conselho Nacional de Desenvolvimento Científico e Tecnológico (CNPq).

\section{REFERÊNCIAS}

AGIM, O. A Cidade de Goiás e os Limites Ambientais: Identificando Causas e Indicando Medidas Preventivas. Goiânia: Ed. a., 2002.

ANACLETO, T. C.; MIZIARA, F. Expansão de fronteiras e ocupação do espaço no cerrado: o caso de Goiás. Geografia. Rio Claro, v. 31, n. 3, p. 527538, 2006.

BAÊTA, Jr J.D. Projeto Manganês no Centro-Sul de Goiás. Relatório Final - Etapa II Goiânia: MME/ DNPM/CPRM, v.7, 1978.

BAÊTA, Jr. J.D., SOUZA, J.O., MORETON, L.C. Programa Levantamentos Geológicos Básicos do Brasil - PLGB. Folha SD.22-Z-C-II - Morro Agudo de Goiás; Folha SD.22-Z-C-V, Goiás; Folha SE.22-X-A-II - Sanclerlândia. Escala 1:100.000. CPRM, Goiânia, 1998. 
BAYER, M. Dinâmica do transporte, composição e estratigrafia dos sedimentos da planície aluvial do Rio Araguaia. Tese (Doutorado em Ciências Ambientais) 2010, UFG, Goiânia, 2010, 104p.

CAMPOS, A. Análise do Comportamento Espacial e Temporal das Temperaturas e Pluviosidades no Estado de Goiás. Goiânia, 2001 (mimeo).

CASSETI, Valter. Ambiente e Apropriação do Relevo. São Paulo: Contexto, 1991.

CHRISTOFOLETTI, A. Geomorfologia. $2^{\circ}$ ed. São Paulo: Editora Edgard Blücher, 188p. 1980.

CREPANI, E.; MEDEIROS, J. S.; AZEVEDO, L.G.; HERNANDEZ FILHO, P.; FLORENZANO, T.G.; DUARTE, V. Curso de sensoriamento remoto aplicado ao zoneamento ecológico econômico. In: $8^{\circ}$ SIMPÓSIO BRASILEIRO DE SENSORIAMENTO REMOTO, Salvador, 1996. Anais... São Paulo: Imagem Multimídia, 1996.

CREPANI, E.; DIAS, RICARDO, R. (org.). Projeto de Gestão Ambiental Integrada da Região do Bico do Papagaio. Zoneamento Ecológico-Econômico. Imperatriz. Vulnerabilidade de Paisagens à Perda de Solos da Folha SB.23V-C. Palmas, Seplan/DZE, 2006.

DNPM. Departamento Nacional de Produção Mineral. $6^{\circ}$ DS. Disponível em: <http://www.dnpm.gov. br/>. Acesso em: 20 set. 2010.

DRAGO, V.A. Geologia da Folha Goiás - SD.22. In: Projeto RadamBrasil: Levantamento de Recursos Naturais. DNPM, Rio de Janeiro, 25:27-300, 1981.

ESTEVAM, L. O tempo da transformação - estrutura e dinâmica da formação econômica de Goiás. Goiânia: ed. do autor, 1998.

FORTES, P.T.F.O. Metalogenia dos Depósitos Auriferos Mina III,Mina Nova e Mina Inglesa, Greenstone Belt de Crixás, Goiás. 1995. Tese (Doutorado em Geociências). Instituto de Geociências, Universidade de Brasília, 1995. 207p.
INCRA. Relatório de Projetos de Reforma Agrária - Projetos de Reforma Agrária Conforme Fases de Implementação. 2011. Disponível em: < http:// www.incra.gov.br/portal/index.php?option $=\mathrm{com}_{-}$ docman\&Itemid=399> Acesso em: 16 dez. 2011.

JOST, H.; FUCK, R.A; DANTAS, E.L.;RANCAN, C.C.; REZENDE, D.B.; SANTOS, E.; PORTELA, J.F.; MATTOS, L.; CHIARINI, M. F.N.; OLIVEIRA, R.C.; SILVA, S.E. Geologia e geocronologia do complexo Uvá, bloco Arqueano de Goiás. Revista Brasileira de Geociências, v. 35, p.01-20, 2005.

LACERDA FILHO, J.V.; FRASCA, A. A. S. Geologia e Recursos Minerais do Estado de Goiás e do Distrito Federal - escala 1:500.000. Goiânia: CRPM/SIC-FUNMINERAL, 2008.

LATRUBESSE, E. M.; CARVALHO, T. M. Geomorfologia do Estado de Goiás e Tocantins. Goiânia: Secretaria de Indústria e Comércio/ Superintendência de Geologia e Mineração do Estado de Goiás, 2006. $128 \mathrm{p}$.

LESSA S. M. \& ANDRADE R.S. Projeto Jussara. DNPM/CPRM, 1971.86p.

MARTINS, J. S. Fronteira: a degradação do outro nos confins do humano. São Paulo: Hucitec, 1997.

MONTALVÃO, R.M.G.. Evolução Geotectônica dos Terrenos Granito- Greenstone de Crixás, Guarinos e Pilar-Hidrolina. 1985. Tese (Doutorado em Geociências), Instituto de Geociências, Universidade de São Paulo, 1958, 372 p.

PEREIRA, R. C. G., LEAL, L. S. M E DA PAZ, R. L. F. Análise da estação chuvosa no periodo de 1999 a 2008 no estado de goiás. In: XV CONGRESSO BRASILEIRO DE METEOROLOGIA. São Paulo, 2008. Anais... São Paulo, 2008.

PHILLIPS, J. D. Deterministic chaos and historical geomorphology: a review and look forward. Geormorphology, 76, pp.109-121, 2006. DOI: http://dx.doi. org/10.1016/j.geomorph.2005.10.004 
RESENDE, M. G.; JOST, H; ORBORNE, G.A; MOL, A.G. Stratigraphy of the Goiás and Faina Greenstone belts, Central Brazil : A New Proposal. Revista Brasileira de Geociências, 28(1):77-94, março de 1998.

NUNES, E. D.; ROMÃO, P. A.; FERREIRA, N. C. Otimização de medidas de entropia da paisagem como subsídio ao planejamento ambiental - Região de Goiânia - GO. Boletim Goiano de Geografia. Goiânia, V.28, n.2,p.125-140, 2008. DOI: http://dx.doi. org/10.5216/bgg.v28i2.5728

RODRIGUES, T. L. DEBIASI, P. SOUZA, R. F. Avaliação da Adequação dos Produtos ASTER GDEM no Auxílio ao Mapeamento Sistemático Brasileiro. III SIMPÓSIO BRASILEIRO DE CIÊNCIAS GEODÉSICAS E TECNOLOGIAS DA GEOINFORMAÇÃO. Recife, 2010. Anais..., Recife, 2010.

SILVA, A. C. S. Mato Grosso permanece grande e forte: a economia mato-grossense após a divisão. Goiânia: Única, 1982.

SOUZA, J.O., Baêta Jr. J.D.A., Moreton H.C. Programa Levantamentos Geológicos Básicos do Brasil, Folhas: SD. 22-ZC- II - Morro Agudo de Goiás. SD. 22-Z-C-V - Goiás e SE.22-X-AII - Sanclerlândia. CPRM, Goiânia, 1999.

STRAHLER, A.N. Physical Geography. $4^{\mathrm{a}}$ edition. New York/London/Sidney/Toronto: John Willey \& Sons, 1952, p.26-127.

TASSINARI, C.C.G. \& MONTALVÃO, R.M.G. 1980. Estudo geocronológico do greenstone belt de Crixás. In: XXXI CONGRESSO BRASILEIRO DE GEOlOGIA, Camburiú, SC. Anais..., Camburiú, p.2752-2759.

TEIXEIRA, A. S. Geologia da região de Goiás-Faina: Simpósio de Geologia Centro-Oeste, Anais..., Goiânia, p. 344-360, 1981.
TOMAZZOLI, E.R. Geologia, Petrologia, Deformação e Potencial Aurifero do Greenstone Belt of the Goiás (GO). Brasil ia. 206 p., 1985 (Dissertação de Mestrado, IG/UnB).

VALENTE, C. R. Geotectonic, geologic evolution and regional geomorphology of the Araguaia river basin, Central Brazil. Teses de Doutorado. 2007. CIAMB-UFG. 2007. 204 p.

VIEIRA, P. A. Caracterização das Unidades Geomorfológicas Geoambientais da Planície do Bananal. 2003. Dissertação de Mestrado. IESA, UFG. 2003. $148 \mathrm{p}$. 